\title{
PEMURNIAN MINYAK JELANTAH DENGAN METODE ADSORBSI MENGGUNAKAN ARANG AKTIF DARI SERBUK GERGAJI KAYU ULIN (Eusideroxylon zwageri)
}

\section{PURIFICATION OF WASTE COOKING OIL ADSORPTION METHOD USING ACTIVE CHARCOAL FROM IRONWOOD SAWDUST (Eusideroxylon zwageri)}

\author{
Syarifuddin Oko, Mustafa, Andri Kurniawan, Nur Afni Muslimin \\ Jurusan Teknik Kimia, Politeknik Negeri Samarinda (POLNES) \\ Jalan Dr. Cipto Mangungkusumo Kampus Gunung Lipan PO Box 1293 \\ Telepon (0541) 260588 (PABX)-260553 Fax 260355, Samarinda 75131, Indonesia \\ E-mail: syarif_oko96@yahoo.com
}

Diterima : 24-03-2020

Direvisi : 27-04-2020

Disetujui : 08-06-2020

\begin{abstract}
ABSTRAK
Minyak goreng merupakan salah satu kebutuhan pokok manusia sebagai bahan pengolah makanan. Penggunaan minyak goreng secara berulang-ulang dan kontinyu pada proses penggorengan akan menurunkan kualitas minyak goreng. Salah satu upaya pengolahan minyak jelantah adalah dengan cara adsorpsi menggunakan arang aktif. Penelitian ini bertujuan untuk mengetahui pengaruh massa arang aktif dan waktu adsorbsi optimal dengan bahan baku serbuk gergaji kayu ulin terhadap penurunan bilangan peroksida,kadar air dan FFA pada minyak jelantah agar memenuhi standar SNI 01-3741:2013. Arang aktif dari serbuk gergaji kayu ulin yang dikarbonisasi dengan furnace pada suhu $500^{\circ} \mathrm{C}$ selama 1 jam lalu aktivasi kimia dengan aktivator $\mathrm{H}_{3} \mathrm{PO}_{4} 10 \%$ selama 24 jam dan mengaktivasi fisika pada suhu $550^{\circ} \mathrm{C}$ selama 1 jam, adapun hasil uji proximate kadar air 0,2498 \%,kadar abu 0,1691\%, kadar volatile matter 5,4067\% dan daya serap iod sebesar 872,2509 mg/gr. Arang aktif yang diperoleh digunakan untuk mengadsorpsi minyak goreng bekas dengan variasi jumlah arang sebanyak 1,5 gram, 2,5 gram, 3,5 gram, 4,5 gram, 5,5 gram, 6,5 gram dan 7,5 gram dalam 50 gram minyak jelantah variasi waktu adsorbsi 40, 60 dan 80 menit. Hasil terbaik dari penelitian ini adalah massa arang aktif 5,5 gram dan waktu adsorpsinya selama 80 menit dengan kadar air 0,0559\% dan daya serapnya sebesar 97,91\%, kadar FFA $0,5576 \%$ dengan penurunan sebesar $84,15 \%$ dan bilangan peroksida 2,4617 mek/kg dengan penurunan sebesar $89,15 \%$.
\end{abstract}

Kata kunci: adsorpsi,arang aktif,bilangan peroksida, free faty acid (FFA),kadar air

\section{ABSTRACT}

Cooking oil is one of the basic human needs as a food processor. The use of cooking oil repeatedly and continuously in the frying process will reduce the quality of cooking oil. One of the waste cooking oil processing efforts is by adsorption using activated charcoal. This study aims to determine the effect of active charcoal mass and optimal adsorption time with ironwood sawdust as a raw material on the reduction of peroxide number, water content and FFA in used cooking oil to meet SNI 01-3741: 2013 standards. Activated charcoal from ironwood sawdust which was carbonized with furnace at $500^{\circ} \mathrm{C}$ for 1 hour was chemically activated with $\mathrm{H}_{3} \mathrm{PO}_{4}$ activator $10 \%$ for 24 hours and physically activated at $550^{\circ} \mathrm{C}$ for 1 hour, while the proximate test results are water content of $0,2498 \%$, ash content of $0,1691 \%$, volatile matter content of $5,4067 \%$, and iod absorption of $872,2509 \mathrm{mg} / \mathrm{gr}$. The 
activated charcoal obtained was used to adsorb used cooking oil with variations in the amount of charcoal as much as 1.5 grams, 2,5 grams, 3,5 grams, 4,5 grams, 5,5 grams, 6,5 grams and 7,5 grams in 50 grams of used cooking oil variation in adsorption time of 40,60, and 80 minutes. The best result of this study was with the variation of 5,5 grams of activated charcoal mass and 80 minutes of adsorption time with 0,0559\% water content and $97,91 \%$ absorption, FFA of 0,5576\% with a decrease of $84,15 \%$ and number peroxide of 2,4617 mek/kg with a decrease of $89,15 \%$.

Keywords: adsorption, activated carbon, peroxide value, free faty acid,moisture

\section{PENDAHULUAN}

M inyak goreng merupakan salah satu kebutuhan pokok manusia sebagai bahan pengolah makanan. Minyak goreng sebagai media penggoreng sangat penting dan kebutuhannya semakin meningkat (Ramdja et al., 2010). Minyak goreng banyak dimanfaatkan oleh masyarakat karena minyak goreng mampu menghantarkan panas, memberikan cita rasa (gurih), tekstur (renyah), warna (coklat), dan mampu meningkatkan nilai gizi (Aladedunye and Przybylski, 2009).

Masyarakat pada umumnya memakai kembali minyak goreng yang sudah dipakai atau disebut minyak jelantah, konsumsi minyak goreng kelapa sawit pada tahun 2018 yaitu sebesar 8.233 ton/tahun. Secara fisik, minyak goreng yang baru dipakai satu-dua kali masih terlihat jernih sehingga cenderung untuk dipakai kembali. Alasan yang paling utama adalah penghematan biaya. Minyak jelantah harganya lebih murah sehingga biaya menjadi lebih kecil dibanding apabila memakai minyak goreng kemasan baru (Suroso, 2013). Penggunaan minyak goreng secara berulang-ulang dan kontinyu pada proses penggorengan akan mengakibatkan terjadinya reaksi degradasi sehingga menurunkan kualitas minyak goreng (Samangun et al., 2017). Minyak goreng yang telah digunakan berulang-ulang akan mengalami penurunan kualitas.

Kerusakan lemak selama proses penggorengan diakibatkan oleh kontak minyak dengan udara, pemanasan yang berlebihan, kontak minyak dengan bahan pangan dan adanya bahan masakan yang gosong saat proses penggorengan. Kerusakan minyak akibat pemanasan dapat dilihat dari perubahan warna, kenaikan kekentalan, kenaikan kandungan asam lemak bebas, kenaikan peroksida dan penurunan bilangan iodium (Hidayati, 2016). Selain itu juga akan terjadi penurunan nilai gizi dari bahan yang digoreng. Hal ini dikarenakan saat dipanaskan pada suhu tinggi disertai kontak dengan udara akan menyebabkan minyak mengalami perubahan kimia seperti proses hidrolisis, oksidasi, polimerisasi, dan reaksi pencoklatan. Proses oksidasi dan polimerisasi dapat merusak sebagian vitamin dan asam lemak esensial yang terdapat dalam minyak sehingga dapat mengakibatkan keracunan dalam tubuh dan berbagai macam penyakit, seperti diare, pengendapan lemak dalam pembuluh darah, dan kanker (Ketaren, 1986). Oleh karena itu pemurnian minyak jelantah perlu diupayakan dengan tujuan penghematan namun tidak membahayakan kesehatan serta mudah dilakukan. Upaya pengolahan minyak jelantah dapat dilakukan dengan berbagai cara, salah satunya dengan cara adsorpsi. Adsorpsi dipilih karena mudah dalam pelaksanaan dan ekonomis.

Adsorben yang biasa digunakan adalah arang aktif (Indah and Hendrawani, 2017). Arang aktif biasanya dibuat dari bahan berbasis karbon, seperti batubara, lignin, bahan lignoselulosa, polimer sintetis, dan limbah karbon. Arang aktif adalah material yang berbentuk butiran atau bubuk yang berasal dari material yang mengandung karbon misalnya tulang, kayu lunak, sekam, tongkol jagung, tempurung kelapa, sabut kelapa, ampas penggilingan tebu, ampas pembuatan kertas, serbuk gergaji, kayu keras, batubara dan sebagainya (Indah and Hendrawani, 2017). Karbon aktif adalah karbon yang dimurnikan, yaitu konfigurasi atom karbonnya dibebaskan dari ikatan dengan unsur lain 
serta pori-porinya dibebaskan dari unsur lain atau kotoran, sehingga permukaan karbon atau pusat aktif menjadi bersih dan lebih luas (Sudrajat and Pari, 2011). Serbuk gergaji kayu mengandung lignin, selulosa, dan hemiselulosa sehingga serbuk gergaji kayu berpotensi sebagai penyerap ion logam (Shukla et al., 2002). Serbuk gergaji kayu ulin memiliki kandungan selulosa,lignin,pentosan,abu dan silica. Kadar selulosa kayu ulin sebesar 58,1\%,kadar lignin kayu ulin sebesar 28,9\%,kadar pentosan 12,7\% sedangkan kadar abu kayu ulin 1,0\% dan kadar silika kayu ulin adalah 0,5\% (Martawijaya et al., 1989). Dengan kandungan selulosa yang cukup tinggi pada kayu ulin ini dapat diolah menjadi arang aktif dengan proses karbonisasi dan aktivasi (Shukla et al., 2002).

Penelitian terkait pemanfaatan arang aktif dari serbuk gergaji kayu ulin untuk meningkatkan kualitas minyak goreng bekas teraktivasi $\mathrm{ZnCl}_{2}$ dengan massa arang aktif 15 gram dan dengan lama waktu pengadukan selama 80 menit. Dengan nilai angka asam sebesar 0,224 $\mathrm{mgKOH} / \mathrm{gram}$, bilangan peroksida sebesar $10 \mathrm{mg}$ eq/gram (Wijayanti et al., 2012). Sedangkan hasil penelitian yang dilakukan oleh (Erawati and Fernando, 2018) tentang pengaruh jenis aktivator yang berbeda yaitu $\mathrm{H}_{3} \mathrm{PO}_{4}, \mathrm{NaOH}, \mathrm{H}_{2} \mathrm{SO}_{4}$, dan $\mathrm{NaCl}$ masing-masing dengan konsentrasi $10 \%(\mathrm{v} / \mathrm{v})$ menunjukkan bahwa agen aktivator yang terbaik dalam pembuatan karbon aktif serbuk gergaji kayu jati menggunakan aktivator $\mathrm{H}_{3} \mathrm{PO}$, yang menghasilkan rendemen arang 89,63\%, kadar air 1,55\%, kadar abu 3,83\%, kadar volatile matter 3,46\%, kadar fixed karbon $92,71 \%$, daya serap terhadap iodium $837,74 \mathrm{mg} / \mathrm{g}$, dan daya serap terhadap benzena sebesar 38,85\%.

Berdasarkan kedua penelitian tersebut didapatkan kesimpulan bahwa pada penelitian yang dilakukan oleh (Wijayanti et al., 2012) tidak diketahui kualitas arang aktif yang digunakan,bilangan peroksida minyak jelantah yang telah diadsorbsi telah memenuhi nilai maksimal bilangan peroksida standar SNI 01-3741:2013 yaitu $10 \mathrm{meq} / \mathrm{gram}$ tetapi masih sangat tinggi sehingga diharapkan bilangan peroksida tersebut masih dapat diturunkan dan belum dilakukan uji kadar air pada minyak jelantah hasil adsorbsi arang aktif. Sedangkan pada penelitian yang dilakukan oleh (Erawati and Fernando, 2018) dapat disimpulkan bahwa $\mathrm{H}_{3} \mathrm{PO}_{4}$ dipilih karena memiliki kadar abu,kadar air dan volatile matter yang terbaik dibandingkan jenis aktivator lainnya.

Maka pada penelitian ini akan dilakukan proses pemurnian suatu minyak jelantah dengan mengetahui pengaruh massa arang aktif dan waktu adsorbsi optimal dengan bahan baku serbuk gergaji kayu ulin terhadap penurunan bilangan peroksida,kadar air dan FFA pada minyak jelantah agar memenuhi standar SNI 01-3741:2013.

\section{METODE PENELITIAN}

\section{Alat}

Alat yang digunakan dalam penelitian ini adalah gelas kimia, neraca digital, buret, screening, shaker, furnace dan oven.

\section{Bahan}

Bahan yang digunakan dalam penelitian ini adalah Serbuk Gergaji Kayu Ulin, Sampel minyak jelantah, Larutan Asam Phospat $\left(\mathrm{H}_{3} \mathrm{PO}_{4}\right) 10 \%$, Aquadest, Indikator PP, Indikator Amilum 1\%, Larutan Iod 0,1N, Larutan Natrium Thiosulfat $\left(\mathrm{Na}_{2} \mathrm{~S}_{2} \mathrm{O}_{3}\right) 0,1 \mathrm{~N}$, Larutan $\mathrm{KI}$ jenuh, Asam Asetat Glasial, Kloroform, Larutan $\mathrm{NaOH} \mathrm{0,1} \mathrm{N,} \mathrm{Etanol,} \mathrm{Kertas} \mathrm{Saring}$ Whatman No.42

\section{Pembuatan Arang Aktif Dari Serbuk Gergaji Kayu Ulin}

Serbuk gergaji kayu ulin dibersihkan dari kotoran dan dikeringkan, selanjutnya dikarbonisasi menggunakan furnace selama 1 jam pada temperatur $500^{\circ} \mathrm{C}$. Arang yang dihasilkan dikecilkan ukurannya menggunakan crusher dan diayak dengan screening $-100+120$ mesh. Selanjutnya arang diaktivasi dengan aktivator $\mathrm{H}_{3} \mathrm{PO}_{4} \quad 10 \%$ dengan perbandingan 1:4 selama 24 jam. Arang yang telah diaktivasi (arang aktif) disaring 
menggunakan kertas saring whatman 42. Kemudian arang aktif dicuci dengan aquadest hingga $\mathrm{pH}$ netral dan dioven pada temperatur $110^{\circ} \mathrm{C}$ selama 3 jam untuk mengurangi kandungan airnya serta didinginkan dalam desikator. Kemudian setelah itu arang aktif diaktivasi secara fisika dengan menggunakan furnace dengan suhu $550^{\circ} \mathrm{C}$ selama 1 jam. Produk arang aktif dianalisa kadar air,kadar abu,kadar zat menguap dan daya serap iod sesuai SNI No. 06-3730-1995.

\section{Pemurnian Minyak Goreng Bekas Dengan Metode Adsorpsi}

Minyak jelantah sebanyak sebanyak 50 gram dimasukkan kedalam 7 gelas kimia, selanjutnya ditambahkan arang aktif serbuk gergaji dengan variasi massa 1,5 gram, 2,5 gram, 3,5 gram, 4,5 gram, 5,5 gram, 6,5 gram dan 7,5 gram. Kemudian diaduk dengan kecepatan 250 rpm selama variasi waktu 40 menit, 60 menit dan 80 menit dan dipanaskan pada suhu $100-110^{\circ} \mathrm{C}$. Minyak jelantah hasil pemurnian di saring menggunakan kertas saring Whatman ukuran 42 dan dianalisa bilangan peroksida,free faty acid (FFA) , kadar air sesuai SNI 01-3741-2013

\section{HASIL DAN PEMBAHASAN}

\section{Karakterisasik Arang Aktif}

Arang sebagai material dalam pemurnian minyak jelantah diperoleh dari karbonasi serbuk gergaji kayu ulin menggunakan furnace. Karbonisasi merupakan proses pembakaran yang mengubah serbuk gergaji kayu ulin menjadi karbon melalui pembakaran yang tidak sempurna dengan menghasilkan $\mathrm{C}_{(\mathrm{s})}, \mathrm{CO}_{(\mathrm{g})}$, dan $\mathrm{H}_{2} \mathrm{O}_{(\mathrm{g})}$. Arang yang diperoleh dikecilkan ukurannya dengan cara digerus dan diayak agar ukurannya menjadi seragam, arang yang diperoleh memiliki luas permukaan yang masih kecil hal ini disebabkan masih banyaknya mineral anorganik dan senyawa tar yang terperangkap pada pori dari arang tersebut. Aktivasi merupakan salah cara untuk meningkatkan luas permukaan, dengan cara aktivasi kimia menggunakan $\mathrm{H}_{3} \mathrm{PO}_{4} 10 \%$ dan dilanjutkan aktivasi secara fisika pada suhu $550^{\circ} \mathrm{C}$. Adapun karakteristik dari arang aktif yang diperoleh melalui aktivasi secara kimia dan fisika ditunjukkan pada table 1 sebagai berikut :

Tabel 1. Analisa Proximate dan daya serap iod Arang Aktif

\begin{tabular}{|clccc|}
\hline \begin{tabular}{c} 
Ukuran $\begin{array}{c}\text { Partikel } \\
\text { (Mesh) }\end{array}$ \\
\hline
\end{tabular} & \multicolumn{1}{c}{$\begin{array}{c}\text { Parameter } \\
\text { Analisa }\end{array}$} & Nilai & $\begin{array}{r}\text { Standar Kualitas Berdasarkan } \\
\text { SNI No.06-3730-1995 }\end{array}$ \\
\cline { 2 - 5 } & Kadar Air & $0,2498 \%$ & Maks. $15 \%$ & Memenuhi Standar \\
\cline { 2 - 5 }$-100+120$ & Kadar Abu & $0,1691 \%$ & Maks. $10 \%$ & Memenuhi Standar \\
\cline { 2 - 5 } & Volatile Matter & $5,4067 \%$ & Maks. $25 \%$ & Memenuhi Standar \\
\cline { 2 - 5 } & $\begin{array}{l}\text { Daya Serap } \\
\text { Iod(Karbonasi) }\end{array}$ & $521,1086 \mathrm{mg} / \mathrm{g}$ & $750 \mathrm{mg} / \mathrm{g}$ & $\begin{array}{c}\text { Belum Memenuhi } \\
\text { Standar }\end{array}$ \\
\cline { 2 - 5 } & $\begin{array}{l}\text { Daya Serap } \\
\text { Iod(Karbonasi) }\end{array}$ & $872,2509 \mathrm{mg} / \mathrm{g}$ & $750 \mathrm{mg} / \mathrm{g}$ & Memenuhi Standar \\
\hline
\end{tabular}

Berdasarkan pada tabel 1, menunjukkan bahwa hasil analisa proximate untuk parameter kadar air, kadar abu dan volatile matter telah memenuhi standar SNI No. 06-3730-1995. Sedangkan untuk analisa daya serap iod pada proses karbonasi menunjukkan daya serap 
iod nya belum memenuhi standar hal ini disebabkan masih adanya pengotor pada pori dari arang tersebut berupa mineral anorganik dan tar dan setelah dilakukan aktivasi kimia serta dilanjutkan dengan aktivasi fisika, analisa daya serap iodnya telah memenuhi standar SNI No. 06-3730-1995.

\section{Pengaruh Waktu Adsorbsi Dan Massa Arang Aktif Terhadap Penurunan Kadar Air}

Kadar air merupakan penentu kualitas minyak. Meskipun kadar asam lemak bebas dalam minyak rendah dan bilangan peroksida rendah, bila kadar air tinggi maka minyak mengandung banyak air dan tingkat hidrolisisnya tinggi sehingga minyak menjadi mudah terurai (Suroso, 2013, Zahra et al., 2013). Adanya air dalam minyak goreng mengakibatkan terjadinya hidrolisa minyak menjadi gliserol dan asam lemak bebas. Proses ini dibantu oleh adanya asam, alkali, uap air, temperatur yang tinggi dan enzim. Air berfungsi untuk memecahkan lemak atau minyak menjadi gliserol dan asam lemak bebas. Terbentuknya ke dua senyawa ini karena terjadi pemutusan rantai trigliserida pada minyak atau lemak.

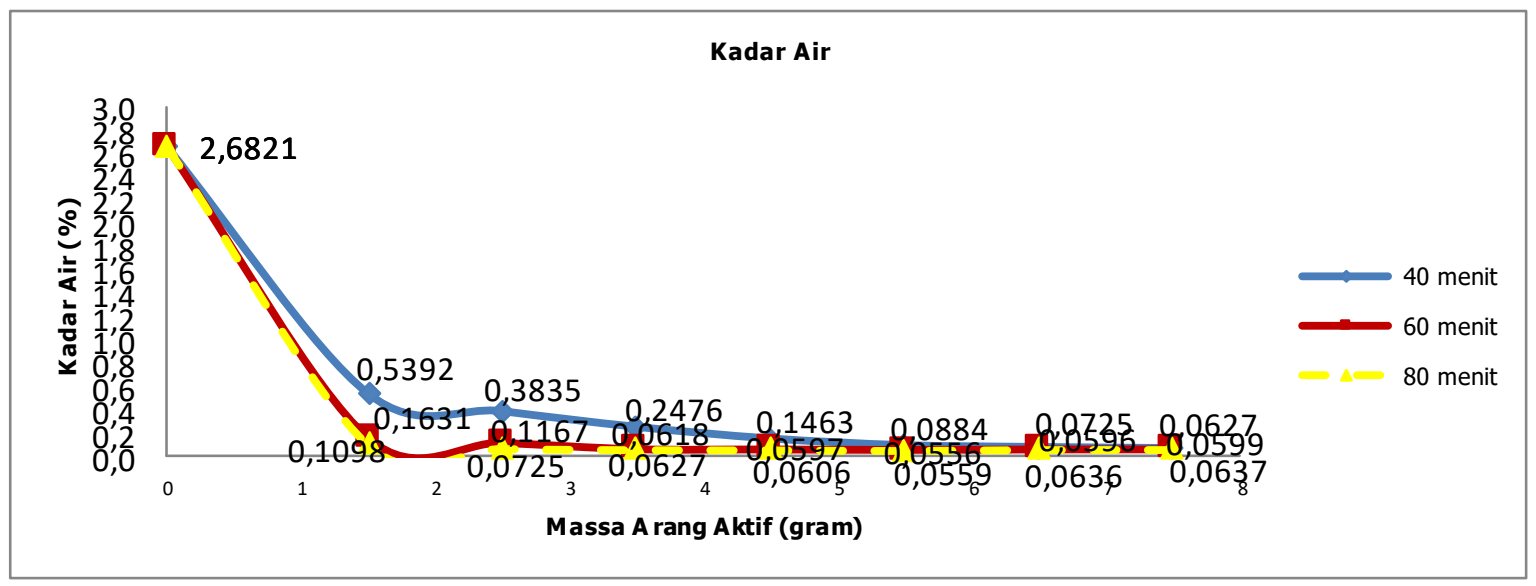

Gambar 1. Pengaruh waktu adsorbsi dan massa arang aktif terhadap penurunan kadar air

Pada gambar 1 diatas dapat dilihat bahwa kadar air sampel minyak jelantah sebelum dilakukan proses adsorbsi dengan arang aktif adalah 2,6821\%. Minyak jelantah kemudian diadsorbsi dengan arang aktif serbuk gergaji kayu ulin dengan variasi waktu 40 menit, 60 menit dan 80 menit serta variasi massa arang aktif 1,5 gram, 2,5 gram, 3,5 gram, 4,5 gram, 5,5 gram, 6,5 gram dan 7,5 gram dalam 50 gram sampel minyak jelantah. Pada gambar 1 dapat dilihat semakin lama waktu adsorpsi,maka penurunan kadar air dalam minyak juga semakin besar. Salah satu contohnya yaitu pada massa arang aktif 1,5 gram dengan waktu adsorpsi 40 menit terjadi penurunan kadar air tetapi penurunan tersebut semakin besar pada waktu adsorbsi 60 menit dan 80 menit. Hal ini disebabkan oleh semakin lama waktu adsorpsi maka waktu kontak antara arang aktif dan minyak jelantah semakin besar sehingga penyerapan berlangsung lebih optimal. Pada gambar yang sama dapat dilihat bahwa semakin banyak arang aktif yang digunakan maka penurunan kadar air dalam minyak juga semakin besar yang disebabkan oleh semakin besarnya luas permukaan adsorpsi sehingga semakin banyak kadar air yang dapat diserap. Tetapi pada variasi massa arang aktif 5,5 gram, 6,5 gram dan 7,5 gram dan waktu adsorbsi 40 menit, 60 menit dan 80 menit penurunan kadar air tidak terlalu signifikan. Hal ini dikarenakan oleh telah tercapainya kondisi adsorpsi optimum sehingga penambahan massa arang aktif dan waktu adsorpsi tidak memberi pengaruh yang cukup besar (Mangallo and Wati, 2019). Kadar air terendah setelah adsorpsi yaitu pada variasi massa 5,5 gram selama 60 menit dan 80 menit masing-masing sebesar $0,0556 \%$ dan 0,0559\% (daya serap sebesar $97,91 \%$ ) yang mana nilai kadar air tersebut telah memenuhi SNI 01-3741-2013 yaitu maksimal 0,15\%. 
Kadar air dalam minyak sangat mempengaruhi mutu minyak tersebut, minyak yang berkadar air tinggi akan cenderung memiliki massa simpan yang pendek(Sudarmadji et al., 1989).

\section{Pengaruh Waktu Adsorbsi Dan Massa Arang Aktif Terhadap Penurunan Free Faty Acid (FFA)}

Asam lemak bebas merupakan sifat penting yang digunakan untuk menentukan atau mengontrol kualitas minyak pangan. Hal ini dikarenakan tingginya asam lemak bebas dapat mempengaruhi cita rasa dan bau pada minyak sehingga menyebabkan penurunan kualitas dari minyak tersebut. Semakin tinggi nilai FFA maka semakin banyak asam lemak bebas yang terdapat dalam minyak tersebut, sehingga asam lemak bebas tersebut akan mempengaruhi sifat kimia, sifat fisik dan stabilitas minyak selama proses penggorengan (Panagan, 2010). Sebagai adsorben,arang aktif mampu menurunkan kadar asam lemak bebas melebihi kadar asam lemak bebas yang dikandung minyak jelantah yang belum diadsorbsi, hal ini disebabkan adanya senyawa - senyawa yang terkandung didalam arang aktif dan mampu menetralisir atau menstabilkan senyawa asam lemak bebas yang terkandung dalam minyak jelantah (Barau et al., 2014).

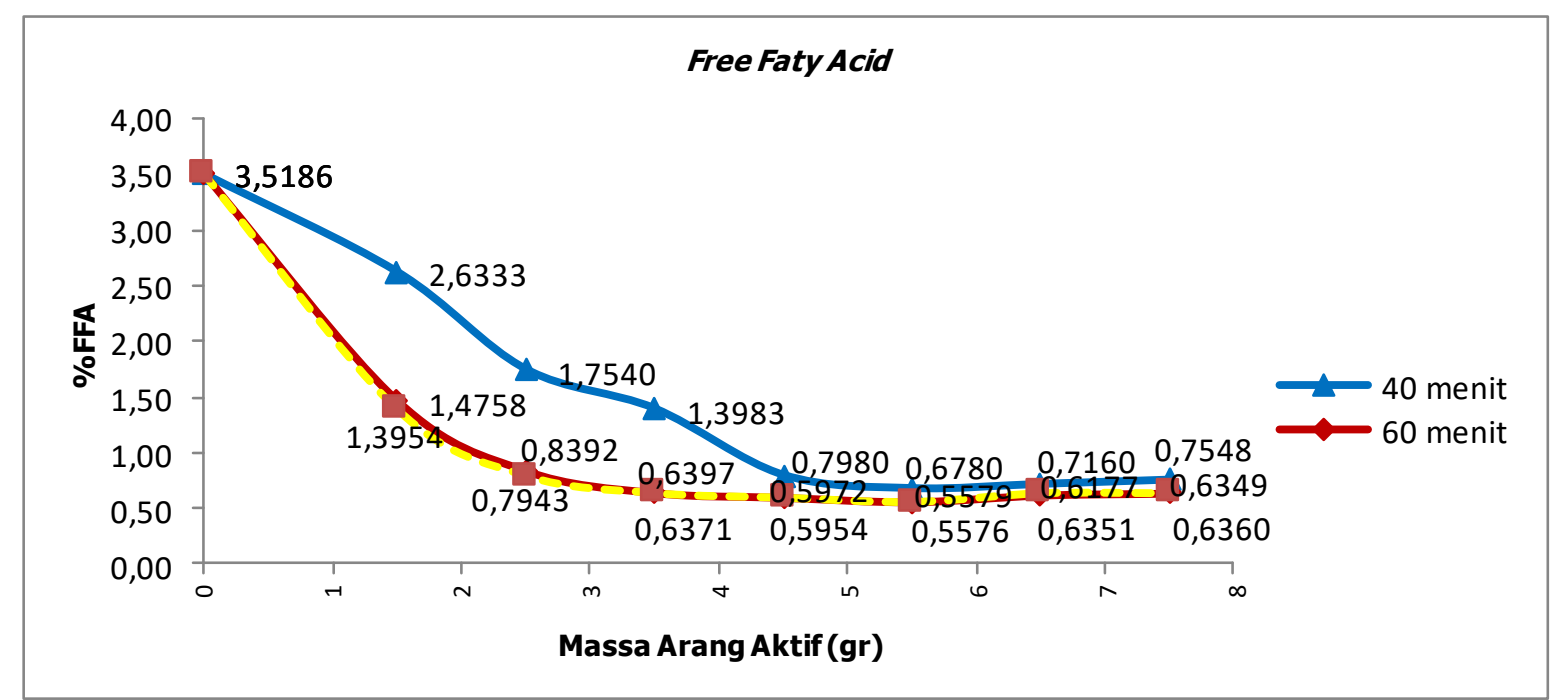

Gambar 2. Pengaruh variasi waktu adsorbsi dan massa arang aktif terhadap penurunan Free Faty Acid (FFA)

Pada gambar 2 dapat dilihat bahwa kadar FFA minyak jelantah sebelum adsorpsi adalah sebesar 3,5186 \% mengalami penurunan setelah diadsorpsi dengan variasi massa 1,5 gram, 2,5 gram, 3,5 gram, 4,5 gram, 5,5 gram, 6,5 gram dan 7,5 gram hal ini dikarenakan semakin banyak arang aktif yang digunakan maka semakin besar luas adsorpsi FFA dalam minyak jelantah. Pada gambar diatas terlihat bahwa semakin lama waktu adsorpsi,maka penurunan kadar FFA dalam minyak juga semakin besar. Salah satu contohnya yaitu pada massa arang aktif 3,5 gram dengan waktu adsorpsi 40 menit terjadi penurunan kadar FFA dalam minyak tetapi penurunan kadar FFA lebih besar pada waktu adsorpsi 60 menit dan 80 menit. Hal ini disebabkan oleh semakin lama waktu adsorpsi maka waktu kontak antara arang aktif dan minyak jelantah semakin besar sehingga penyerapan FFA berlangsung lebih optimal. Pada gambar yang sama dapat dilihat bahwa variasi massa arang aktif 6,5 gram dan 7,5 gram dan waktu adsorbsi 40 menit, 60 menit dan 80 menit terjadinya kenaikan kadar FFA yang disebabkan oleh semakin banyak arang aktif yang ditambahkan maka semakin kecil perbedaan konsentrasi antara arang aktif dan fase cairnya (minyak hasil adsorpsi) sehingga driving force semakin kecil dan menyebabkan 
FFA yang dapat berpindah dari minyak ke arang aktif semakin kecil. Variasi massa arang aktif dan waktu adsorpsi terbaik yaitu pada massa arang aktif 5,5 gram selama 80 menit sebesar $0,5576 \%$ dengan penurunan sebesar $84,15 \%$. Nilai kadar FFA minyak jelantah setelah adsorpsi tersebut telah memenuhi SNI 01-3741-2013 yaitu maksimal 0,6\%.

\section{Pengaruh Waktu Adsorbsi Dan Massa Arang Aktif Terhadap Penurunan Bilangan Peroksida}

Bilangan peroksida sangat penting untuk identifikasi tingkat oksidasi minyak. Minyak yang mengandung asam lemak tidak jenuh dapat teroksidasi oleh oksigen yang menghasilkan suatu senyawa peroksida (Aminah, 2010). Asam lemak tidak jenuh penyusun suatu trigliserida dapat mengikat oksigen pada ikatan rangkapnya, sehingga okidasi terjadi pada ikatan tak jenuh dalam asam lemak. Makin besar bilangan peroksida, makin besar pula derajat kerusakan pada minyak (Mukmillah and Istianah, 2009). Jumlah peroksida yang terdapat dalam minyak ditetapkan dengan metode iodometri. Pada metode ini iod mereduksi peroksida-peroksida yang terbentuk dalam minyak (Suroso, 2013). Bilangan peroksida menyatakan jumlah ekivalen hidroperoksida yang terbentuk setiap $1000 \mathrm{~g}$ sampel. Hidroperoksida terbentuk dari reaksi radikal bebas peroksida dengan asam lemak tak jenuh pada minyak (Ketaren, 1986). Nilai peroksida pada dasarnya dapat digunakan untuk mengikuti perubahan bau tengik, meskipun tidak selalu tepat, sebab pembentukan peroksida sangat sensitif terhadap perubahan suhu sehingga menuntut ketelitian tinggi dalam menganalisisnya. Selama berlangsungnya oksidasi minyak, nilai peroksida akan meningkat kemudian menurun sehingga terdapat keadaan dimana jumlah peroksida yang terbentuk mencapai maksimum. Reaksi oksidasi pada minyak dapat dihambat dengan menggunakan antioksidan (Panagan, 2010).

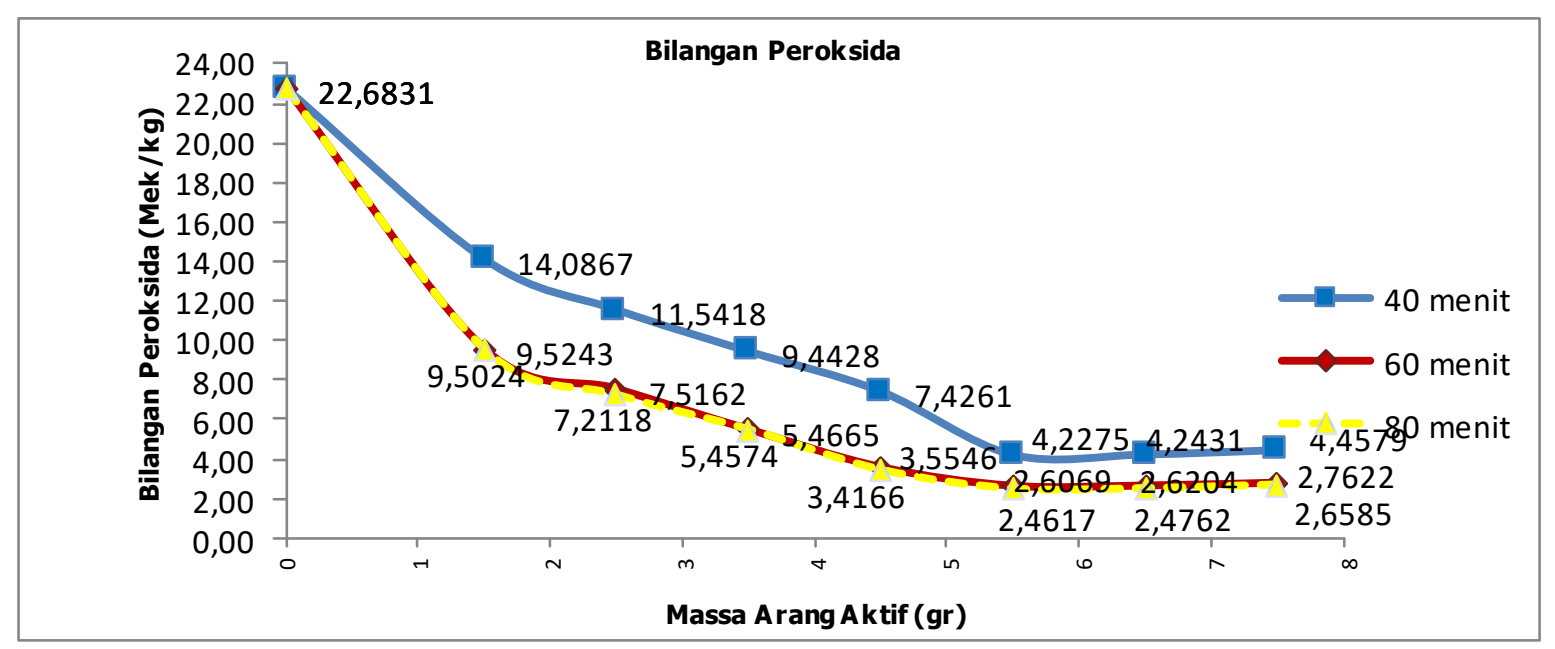

Gambar 3. Pengaruh Waktu Adsorbsi Dan Massa Arang Aktif Terhadap Penurunan Bilangan Peroksida

Pada gambar 3 diatas dapat diketahui bahwa bilangan peroksida sampel minyak jelantah sebelum diadsorbsi yaitu $22,6845 \mathrm{mek} / \mathrm{kg}$. Setelah dilakukan adsorbsi menggunakan arang aktif dengan variasi massa 1,5 gram, 2,5 gram, 3,5 gram, 5,5 gram, 4,5 gram, 6,5 gram dan 7,5 gram dalam 50 gram sampel minyak jelantah dan variasi waktu adsorbsi selama 40 menit, 60 menit dan 80 menit, menunjukkan terjadinya penurunan bilangan peroksida. Akan tetapi pada variasi massa 1,5 gram dan 2,5 gram pada waktu adsorpsi 40 menit, meskipun telah terjadi penurunan bilangan peroksida yang cukup besar tetapi belum memenuhi standar SNI 01-3741-2013 karena massa arang aktif yang digunakan masih sedikit sehingga luas permukaan adsorbsinya kurang dan juga disebabkan oleh waktu 
adsorbsi yang relatif lebih singkat sehingga kontak antara sisi aktif arang aktif dengan peroksida yang terkandung dalam minyak jelantah tidak dapat mengadsorbsi secara optimal. Sedangkan pada variasi massa arang akti 6,5 gram dan 7,5 gram dengan waktu adsorpsi selama 40 menit, 60 menit dan 80 menit terlihat terjadinya kenaikan bilangan peroksida yang disebabkan oleh semakin banyak arang aktif yang ditambahkan maka semakin kecil perbedaan konsentrasi antara arang aktif dan fase cairnya (minyak hasil adsorpsi) sehingga driving force semakin kecil dan menyebabkan bilangan peroksida yang dapat berpindah dari minyak ke arang aktif semakin kecil (Apecsiana et al., 2016). Hasil terbaik didapatkan pada variasi massa 5,5 gram selama 80 menit yaitu sebesar 2,4617 mek/kg dengan penurunan $89,15 \%$ dan telah memenuhi standar SNI 01-3741-2013 yaitu maksimal sebesar 10 mek/kg.

\section{KESIMPULAN}

Berdasarkan penelitian yang telah dilakukan,dapat disimpulkan bahwa variasi terbaik yang digunakan untuk adsorbsi yaitu pada massa arang aktif 5,5 gram dan waktu adsorpsi 80 menit dengan kadar air sebesar 0,0559\% dengan daya serap sebesar 97,91\%, kadar FFA sebesar $0,5576 \%$ dengan penurunan sebesar $84,15 \%$ dan bilangan peroksida sebesar 2,4617 mek/kg dengan penurunan sebesar $89,15 \%$ dan hasil analisa tersebut telah memenuhi standar SNI 01-3741-2013.

Semakin banyak massa arang aktif dan semakin lama waktu adsorpsi, menunjukkan bahwa adsorpsi minyak jelantah telah terjadi penurunan cukup signifikan terhadap kadar air, kadar FFA dan bilangan peroksida.

\section{UCAPAN TERIMA KASIH}

Penulis mengucapkan banyak terima kasih kepada P3M POLNES atas dukungannya sehingga penelitian ini dapat diselesaikan dengan tepat waktu.

\section{DAFTAR PUSTAKA}

Aladedunye, F. A. \& Przybylski, R. 2009. Degradation And Nutritional Quality Changes Of Oil During Frying. Journal Of The American Oil Chemists' Society 86(2) : 149-156.

Aminah, S. 2010. Bilangan Peroksida Minyak Goreng Curah Dan Sifat Organoleptik Tempe Pada Pengulangan Penggorengan. Jurnal Pangan Dan Gizi 1(1) : 7-14.

Apecsiana, F., Kristianto, H. \& Andreas, A. 2016. Adsorpsi Ion Logam Tembaga Menggunakan Karbon Aktif Dari Bahan Baku Kulit Salak. Seminar Nasional Teknik Kimia Kejuangan : 1-7.

Barau, F., Nuryanti, S. \& Pursitasari, I. D. 2014. Buah Mengkudu (Morinda Citrifolia L.) Sebagai Pengadsorbi Minyak Jelantah. Jurnal Akademika Kimia 4(1) : 8-16.

Erawati, E. \& Fernando, A. 2018. Pengaruh Jenis Aktivator Dan Ukuran Karbon Aktif Terhadap Pembuatan Adsorbent Dari Serbik Gergaji Kayu Sengon (Paraserianthes Falcataria). Jurnal Integrasi Proses 7(2) : 58-66.

Hidayati, F. C. 2016. Pemurnian Minyak Goreng Bekas Pakai (Jelantah) Dengan Menggunakan Arang Bonggol Jagung. Jipf (Jurnal Ilmu Pendidikan Fisika) 1(2) : 6770.

Indah, D. R. \& Hendrawani, H. 2017. Upaya Menurunkan Kadar Ion Logam Besi Pada Air Sumur Dengan Memanfaatkan Arang Ampas Tebu. Hydrogen: Jurnal Kependidikan Kimia 5(2): 57-66.

Ketaren, S. 1986. Pengantar Teknologi Minyak Dan Lemak Pangan. UI Press, Jakarta.

Mangallo, B. \& Wati, S. I. 2019. Efektivitas Arang Aktif Kulit Salak Pada Pemurnian Minyak Goreng Bekas. Chemistry Progress 7 (2) : 58-65. 
Martawijaya, A., Kartasujana, I., Mandang, Y., Prawira, S. \& Kadir, K. 1989. Atlas Kayu Indonesia Jilid II. Pusat Penelitian Dan Pengembangan Hasil Hutan, Bogor, Indonesia.

Mukmillah, L. \& Istianah, R. 2009. Analisis Mutu Minyak Jelantah Hasil Peremajaan Menggunakan Tanah Diatomit Alami Dan Terkalsinasi. Jurnal Kimia Valensi 1(4) : 171-180.

Panagan, T. 2010. Pengaruh Penambahan Bubuk Bawang Merah (Allium Ascalonicum) Terhadap Bilangan Peroksida Dan Kadar Asam Lemak Bebas Minyak Goreng Curah. Universitas Sriwijaya, Palembang 6(5) : 17-19.

Ramdja, A. F., Febrina, L. \& Krisdianto, D. 2010. Pemurnian Minyak Jelantah Menggunakan Ampas Tebu Sebagai Adsorben. Jurnal Teknik Kimia 17(1) : 7-14.

Samangun, T., Nasrun, D. \& Iskandar, T. 2017. Pemurnian Minyak Jelantah Menggunakan Arang Aktif Dari Sekam Padi. Eureka: Jurnal Penelitian Teknik Sipil Dan Teknik Kimia $1(2): 1-7$.

Shukla, A., Zhang, Y.-H., Dubey, P., Margrave, J. \& Shukla, S. S. 2002. The Role Of Sawdust In The Removal Of Unwanted Materials From Water. Journal Of Hazardous Materials 4(95) : 137-152.

Sudarmadji, S., Suhardi \& Haryono, B. 1989. Analisa Bahan Makanan Dan Pertanian, Liberty Yogyakarta Bekerja Sama Dengan Pusat Antar Universitas Pangan Dan ....

Sudrajat, R. \& Pari, G. 2011. Arang Aktif. Teknologi Pengolahan Dan Masa Depannya. Badan Penelitian Dan Pengembangan Kehutanan. Jakarta.

Suroso, A. S. 2013. Kualitas Minyak Goreng Habis Pakai Ditinjau Dari Bilangan Peroksida, Bilangan Asam Dan Kadar Air. Jurnal Kefarmasian Indonesia 3(2) : 77-88.

Wijayanti, H., Nora, H. \& Amelia, R. 2012. Pemanfaatan Arang Aktif Dari Serbuk Gergaji Kayu Ulin Untuk Meningkatkan Kualitas Minyak Goreng Bekas. Konversi 1(1) : 2733.

Zahra, S. L., Dwiloka, B. \& Mulyani, S. 2013. Pengaruh Penggunaan Minyak Goreng Berulang Terhadap Perubahan Nilai Gizi Dan Mutu Hedonik Pada Ayam Goreng. Animal Agriculture Journal 2(1) : 253-260. 